\title{
Article \\ Exploring the Rheology of a Seismogenic Zone by Applying Seismic Variation
}

\author{
Chun-Fu Liao $(\mathbb{D}$, Strong Wen *(D), Chau-Huei Chen and Ying-Nien Chen
}

Citation: Liao, C.-F.; Wen, S.; Chen, C.-H.; Chen, Y.-N. Exploring the Rheology of a Seismogenic Zone by Applying Seismic Variation. Appl. Sci. 2021, 11, 8847. https://doi.org/ 10.3390/app11198847

Academic Editor: Snježana Markušić

Received: 23 August 2021

Accepted: 15 September 2021

Published: 23 September 2021

Publisher's Note: MDPI stays neutral with regard to jurisdictional claims in published maps and institutional affiliations.

Copyright: (c) 2021 by the authors. Licensee MDPI, Basel, Switzerland. This article is an open access article distributed under the terms and conditions of the Creative Commons Attribution (CC BY) license (https:/ / creativecommons.org/licenses/by/ $4.0 /)$.
Department of Earth and Environmental Sciences, National Chung Cheng University, Chiayi 62102, Taiwan; tofu416@hotmail.com (C.-F.L.); seichen@eq.ccu.edu.tw (C.-H.C.); noise0221@gmail.com (Y.-N.C.)

* Correspondence: strong@eq.ccu.edu.tw

Featured Application: A 4D tomographic technique is utilized to investigate the variation of rheology around the fault zone.

Abstract: Although the study of spatiotemporal variation of a subsurface velocity structure is a challenging task, it can provide a description of the fault geometry as well as important information on the rheological changes caused by fault rupture. Our main objective is to investigate whether rheological changes of faults can be associated with the seismogenic process before a strong earthquake. For this purpose, a 3D tomographic technique is applied to obtain $\mathrm{P}$ - and S-wave velocity structures in central Taiwan using travel time data. The results show that temporal variations in the Vs structure in the source area demonstrate significant spatiotemporal variation before and after the Chi-Chi earthquake. We infer that, before the mainshock, Vs began to decrease (and Vp/Vs increased) at the hanging wall of the Chelungpu fault, which may be induced by the increasing density of microcracks and fluid. However, in the vicinity of the Chi-Chi earthquake's source area, Vs increased (and Vp/Vs decreased), which may be attributed to the closing of cracks or migration of fluid. The different physical characteristics at the junctional zone may easily generate strong earthquakes. Therefore, seismic velocity changes are found to be associated with a subsurface evolution around the source area in Taiwan. Our findings suggest that monitoring the Vp and Vs (or Vp/Vs) structures in high seismic potential zones is an important ongoing task, which may minimize the damage caused by future large earthquakes.

Keywords: temporal velocity variation; subsurface velocity structure; seismogenic process; crustal rock characteristics; $4 \mathrm{D}$ tomographic technique

\section{Introduction}

Changes in the physical properties of a fault zone before an earthquake rupture have become an important issue that scientists attempt to explore. Generally, the most popular methods for the topic of earthquake precursors are ionospheric anomalies [1-3] and seismic activity $[4,5]$. They can include variations in rock properties or pore pressures during the inter-seismic period, but these characteristics still cannot be directly observed around the seismogenic zone. Results of seismic velocity measurements reveal some information about the potential role of crustal rock strength and pore pressure in crustal dynamics. From a wave propagation simulation, it is known that $\mathrm{Vp}$ is inversely proportional to the crack density and $\mathrm{Vs}$ is proportional to the fractional volume of the fluid content in fractured rock [6]. In addition, for the velocity structures of Vp and Vs, the Vp/Vs ratio is correlated to Poisson's ratio; therefore, they are regarded as important parameters in research into crustal rock characteristics [6,7]. Poisson's ratio reflects the porosity, degree of crushing, and hydraulic pressure of rock formation.

Many factors such as the composition of rock, orientation of cracks, pore pressure, temperature, and fluid saturation would affect the $\mathrm{Vp} / \mathrm{Vs}$ ratio. Since most seismic events occur in active fault zones, the $\mathrm{Vp} / \mathrm{Vs}$ ratio can be used to determine if pressure changes 
will cause cracks to affect the velocity structure, which may result in gas or fluid migration and further large changes in pore pressure $[8,9]$. Therefore, the relationship between the characteristics of a fault zone and the distribution of the $\mathrm{Vp} / \mathrm{Vs}$ ratio can be explored through three-dimensional (3D) tomography inversion. Furthermore, velocity structures can also be utilized to detect the attitude of subsurface formation and a brief overview of interface properties and features. Based on the above advantages, the results obtained in this study can be used to further understand the spatiotemporal evolution of fault materials.

Recently, some studies about seismic velocity variation have been conducted on the basis of the rupture of rocks caused by faulting [10], migration of magmatic fluids accompanying volcanic activity [11,12], and dilatancy and fluid migration before earthquakes [13], among others. The authors of [6] also described the variations in Vp before and after the 1999 Chi-Chi earthquake and the corresponding variations in Vp/Vs. Although there were no significant changes in $\mathrm{Vp}$, after the occurrence of the Chi-Chi earthquake, deeper regions of the low-velocity anomaly appeared to have further expanded. The $\mathrm{Vp} / \mathrm{Vs}$ model showed a substantial change reflecting an outward shift of the fluid-filled fractured source region. These changes are attributed to a localized stress change caused by the slip of the Chi-Chi rupture. The authors of [14] stated that the relationship between the velocity structure and time can be applied in earthquake forecasting and prediction, volcano warning systems, geothermal exploration, oil and gas reservoir assessment, and carbon dioxide capture and storage. However, the study of spatiotemporal variations of subsurface velocity structures is still a challenging work.

For the Taiwan region, from studies using 3D velocity models, similar results were discovered [15-18]; however, temporal variation was not considered in these 3D models. In 1999, the disastrous Chi-Chi earthquake $\mathrm{M}_{\mathrm{L}} 7.3$ occurred in central Taiwan and greatly affected Taiwanese society. In addition, although considerable research has been conducted to better understand the changes in the velocity structure in response to seismic events in central Taiwan, few studies have emphasized the significance of the velocity structure in relation to time. Therefore, this study aims to determine the impact of the Chi-Chi earthquake in central Taiwan before and after the event in order to understand the behavior of subsurface velocity structures. The main objectives of this research can be divided into three parts. First verifying the resolution of the model in each period. Next, detecting the uncertainty of the difference in different periods. Finally, the time evolution of the imaging velocity structure.

\section{Geological Setting}

Taiwan is situated on the collision boundary between the Eurasian and Philippine Sea Plates. Since the late Miocene, the southeast of the rifted continental margin, which was part of the Eurasian Plate, has been colliding with the Philippine Sea Plate, leading to the Taiwan orogeny [19]. The Philippine Sea Plate moves in a NW direction with a convergence rate of $8.2 \mathrm{~cm} /$ year [20]. The ongoing orogenic process causes a series of imbricate foldthrust belts in the Western Foothills of Taiwan. Therefore, central Taiwan is composed of a complex system of belts, including the Changhua Fault (CHF), Chelungpu Fault (CLF), Shuangtung Fault (STF), Shuilikeng Fault (SKF), Lishan Fault (LF), and Longitudinal Valley Fault (LVF) (see Figure 1).

The great 1999 Chi-Chi earthquake $\left(\mathrm{M}_{\mathrm{L}}=7.3\right.$; depth $\left.=8 \mathrm{~km}\right)$ that occurred at the CLF has received the most attention. The SKF is on the east of the foreland basin, and to its west are the STF, CLF, and CHF. They represent the major geological structures of central Taiwan. In addition, the continental margin of the Eurasian Plate contains several Eocene rift basins [21-23], of which the Hsuehshan Basin holds an important part of the Taiwan orogenic belt [21]. The sedimentary stratum beneath the foreland basin can reach more than $6 \mathrm{~km}$ in thickness, and the deformation front is also included [24].

The Eocene rocks of the Hsuehshan Basin now topographically occupy the higher ground and structurally overlie Pleistocene rocks of the foreland basin along the SKF $[25,26]$. Among them, the Peikang Basement High is located in western Taiwan, which impedes the 
orogenic process. Moreover, central Taiwan is the transition zone of the Peikang Basement High and the Central Range.

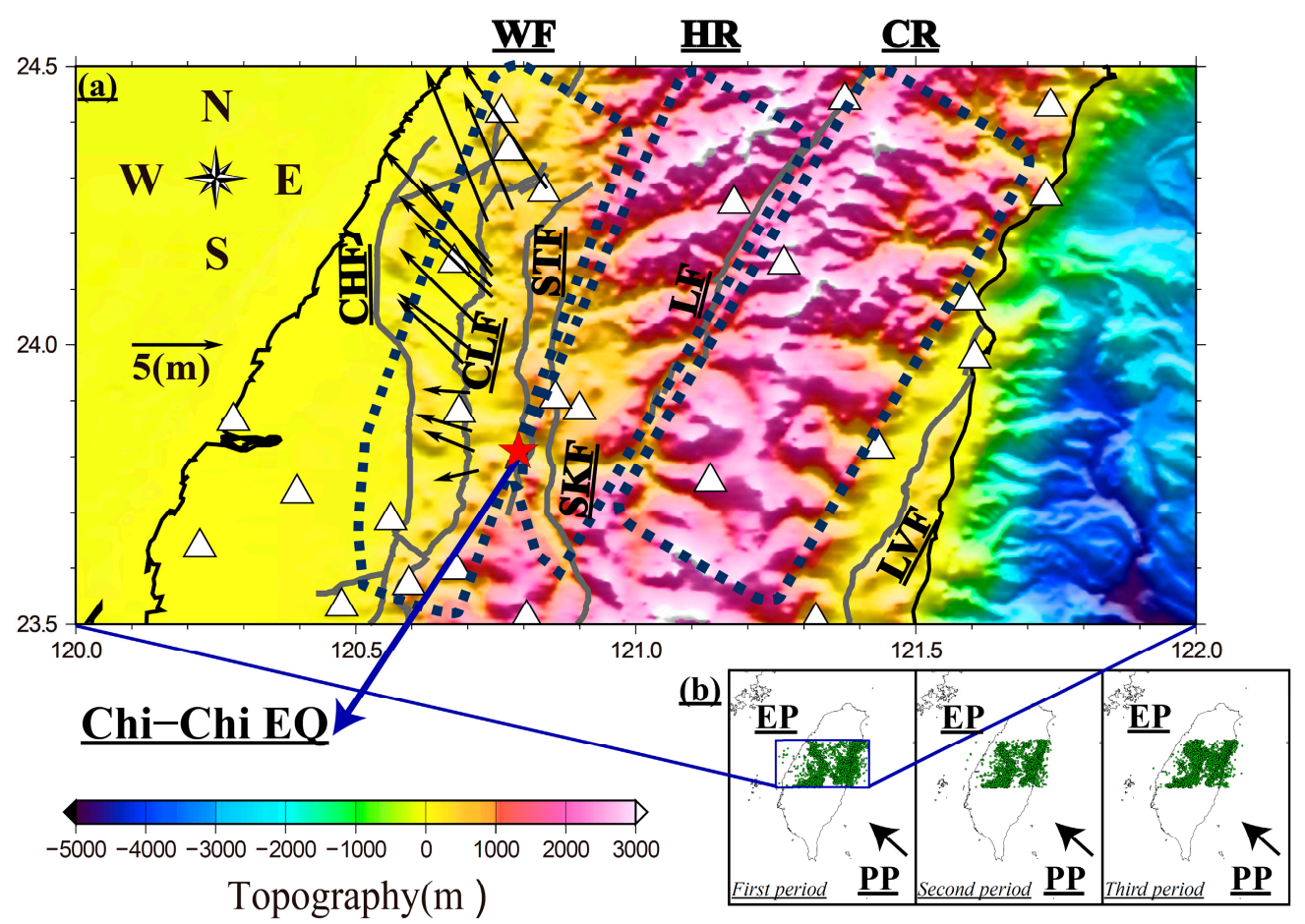

Figure 1. (a) Fault setting in central Taiwan and seismic stations used in this study. The black arrows indicate the near-field GPS horizontal coseismic displacement. (b) Seismic distributions at different time periods. In the period I, there were 6075 events and 93,870 ray paths within the study area. In the period II, there were 5970 events and 96,862 ray paths within the study area. In the period II, there were 8234 events and 135,391 ray paths within the study area. EP: Eurasian Plate; PP: Philippine Sea Plate; WF: Western Foothills; HR: Hsuehshan Range; CR: Central Range; CHF: Changhua Fault; CLF: Chelungpu Fault; STF: Shuangtung Fault; SKF: Shuilikeng Fault; LF: Lishan Fault; LVF: Longitudinal Valley Fault.

According to thin-skinned thrust theory [27], a basal detachment, composed of brittle structures, may exist beneath the fold thrust belts in the Western Foothills of Taiwan. During the collision of plates, structures above the basal detachment form a series of imbricate fold-thrust belts in the shallow layer. However, when the rift-related basin bounding faults were reactivated as a result of the collision process, the crust deformation proceeded toward the deeper parts and caused the underlying basement to be uplifted and exhumed $[28,29]$. This orogenic process can lead to destructive deformity on the surface, which leads to heavy casualties and property losses. In addition, the seismicity can occur along the reactivating rift-related faults, and steeply inclined seismic clusters extending into the lower crust are exhibited [28,30,31].

\section{Data and Methods}

In this research, we utilized the massive volume of the seismic events compiled by the Central Weather Bureau Seismic Network (CWBSN) from January 1991 to December 2003. We divided this time span into three segments to investigate velocity structures in different time periods, namely, 1 January 1991-31 December 1995; 1 January 199619 September 1999; 1 January 2001-31 December 2003 (hereinafter, period I, period II, and period III, respectively) (see Figure $1 \mathrm{~b}$ ). We excluded the days immediately before and after the Chi-Chi earthquake because of complicated source effects that make some seismic events unsuitable to be adopted as a point source; therefore, these data could not be used for tomography [32]. This study suggests that a large earthquake caused by stress 
adjustment makes the subsurface structure unstable, so the data for the year after the Chi-Chi earthquake was eliminated.

In this study, we used the travel times of P- and S-waves from earthquakes located inside the study area. Our study area stretched from $120.0^{\circ} \mathrm{E}$ to $122.0^{\circ} \mathrm{E}$ in longitude and from $23.5^{\circ} \mathrm{N}$ to $24.5^{\circ} \mathrm{N}$ in latitude. Earthquakes with magnitudes equal to or greater than 1.0 were considered, and data with poor location quality were excluded. Twenty-five stations were chosen in the study area, and at least 10 readings of each earthquake event were recorded, as the amount of observation of the matched earthquake event arrival affects the quality of the location of the earthquake; fewer observations result in poor location quality.

We applied seismic travel time data for tomography inversion by local tomography software [33]. The local tomography software was modified according to the bending-ray tracing algorithm by [34]. First, we utilized the Goal function [35] to detect the initial locations of the earthquakes. A straight path was drawn from the hypocenter to the station to locate the turning point at the midpoint and create a new path in sequence. Then, the corresponding travel time residue was calculated and the one with the minimum value was set as the ray path [28]. Finally, travel-time inversion was performed using the LSQR algorithm $[36,37]$ to measure the P- and S-wave velocity anomalies and for obtaining the source parameters (four parameters for each seismic event). Furthermore, these results are fed back on a 3D grid for performing iterative inversion calculations until the iteration number or the travel-time residual value was less than the threshold value.

The study area was divided into numerous grids to invert the velocity variation. The grid was centered $\left(121^{\circ} \mathrm{E}, 24^{\circ} \mathrm{N}\right)$ on the positive and negative sides of the $\mathrm{x}_{-}, \mathrm{y}-$, and $\mathrm{z}$-axes to $200 \mathrm{~km}$ and had dimensions of $5 \times 5 \times 5 \mathrm{~km}^{3}$. As a single-grid azimuth may cause artifacts [38], this study averaged the results from four angles- $0^{\circ}, 22^{\circ}, 45^{\circ}$, and $67^{\circ}$ - to reduce any grid dependency. We integrated different combinations of $\mathrm{Vp}$ and $\mathrm{Vs}$ damping values to obtain the optimal model through the trial and error process. Finally, we selected the appropriate $\mathrm{Vp}$ and $\mathrm{Vs}$ damping parameters that would give results with the stable travel-time residual (RMS). The different combinations of the Vp and Vs damping parameters for each stage are 15 and 15, respectively. In addition, the initial velocity model often plays a decisive role in the problem of velocity inversion. Therefore, for the selection of the velocity structure in this study area, we chose the one that closely approximates the real velocity structure model to facilitate the inversion. We applied the one-dimensional (1D) velocity model adopted by [17] as the initial $1 \mathrm{D}$ velocity structure in this study.

This formula refers to the method of [32], and the description is simplified. In the subsequent study, the following formula was applied on the temporal variation in the velocity structure:

$$
\left[\frac{\left(V_{n}^{i+1}-V_{n}^{i}\right)}{V_{n}^{i}}\right] \times 100 \%
$$

where $V$ is the velocity, $i$ is the number of periods, and $n$ is the number of grids. Finally, the velocity perturbation model was obtained to explore the temporal variations in the velocity structure in central Taiwan.

\section{Model Examination}

An important objective of this study was to investigate the local velocity structural changes before and after the occurrence of strong earthquakes in central Taiwan. The evolution of velocity models in different time periods before and after the Chi-Chi earthquake is discussed. Through this analysis, we can further understand the seismogenic process before the earthquake, which is of great importance for future strong earthquake monitoring in central Taiwan.

In this study, the travel time data of the earthquake events compiled by the CWBSN were used, and the whole study time interval was divided into three periods for the inversion of 3D temporal velocity models for central Taiwan. To understand the reliability of the inversion results, a checkerboard test was used to verify the resolution at different depths. 
We utilized the 1D velocity model adopted by [17] and added a $\pm 8 \%$ perturbation to $\mathrm{Vp}$ and $\mathrm{Vs}$ to generate a new 3D velocity model in the form of a checkerboard (grid dimensions: $10 \times 10 \mathrm{~km}^{2}$ in horizontal space). Utilizing this $3 \mathrm{D}$ velocity model, the assumed travel times of $\mathrm{P}$ - and $\mathrm{S}$-waves are calculated. The results yielded by the checkerboard test for each period are shown in Figures 2-4.

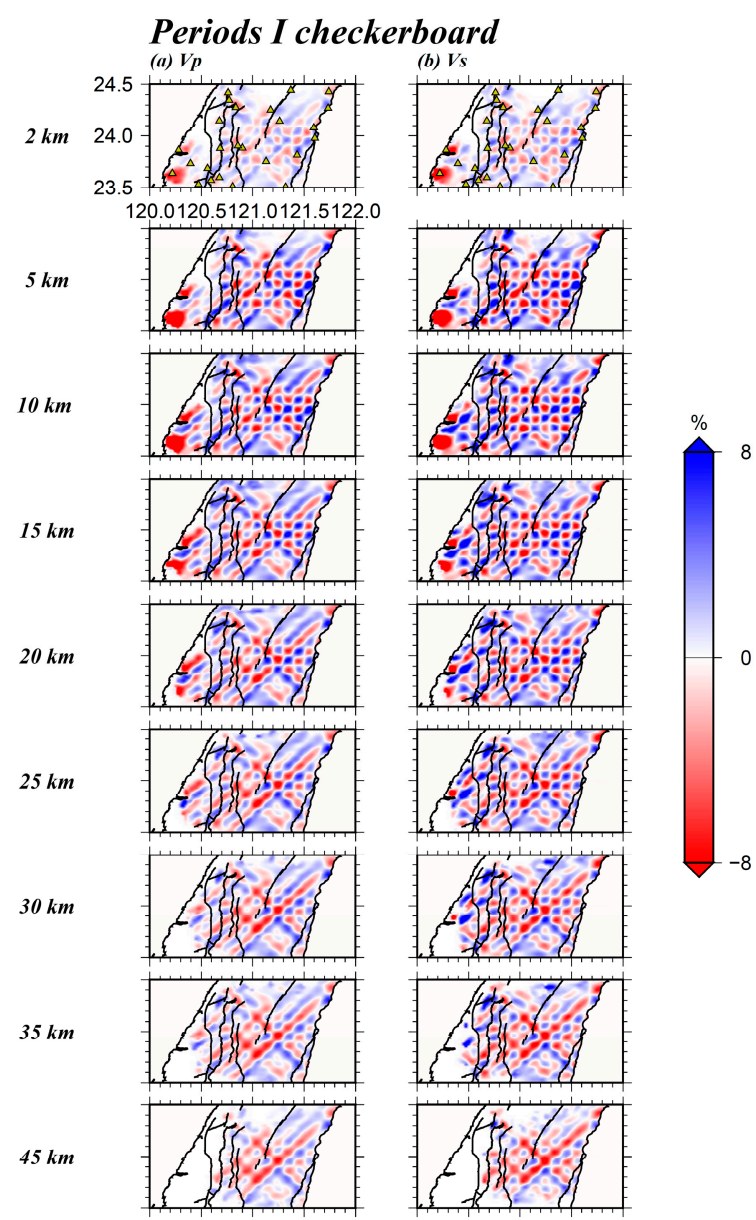

Figure 2. Perturbations of $\pm 8 \%$ of $\mathrm{Vp}$ and $\mathrm{Vs}$ were added to generate a new 3D velocity model in the form of a checkerboard (grid distance: $10 \times 10 \mathrm{~km}^{2}$ ). Yellow triangles represent the stations. (a) Period I checkerboard of Vp. (b) Period I checkerboard of Vs.

The checkerboard test reflected the density of the ray paths at different depths, which could explain the resolution at different depths and confirm the reliability of the velocity model. The results show that both $\mathrm{Vp}$ and $\mathrm{Vs}$ have poor resolution at shallow depths of $0-5 \mathrm{~km}$; this is because, near the surface, the ray path is nearly perpendicular to the station, resulting in an incomplete reflection of the lateral variation in the velocity structure. At depths of 10-25 km, excellent resolution was obtained because of a high ray density. These results suggest that the $3 \mathrm{D}$ velocity model of this area has a very high level of reliability for different time periods. The 3D velocity models of each period are shown in the Appendix A.

To verify the impact of artifacts, this study designed another test [32] restoration by identical synthetic models using two data subsets corresponding to different periods (Figures 5-7).

The test results using data of periods I and II in the proposed model with the variation in the synthetic manner are shown in Figure 8. 


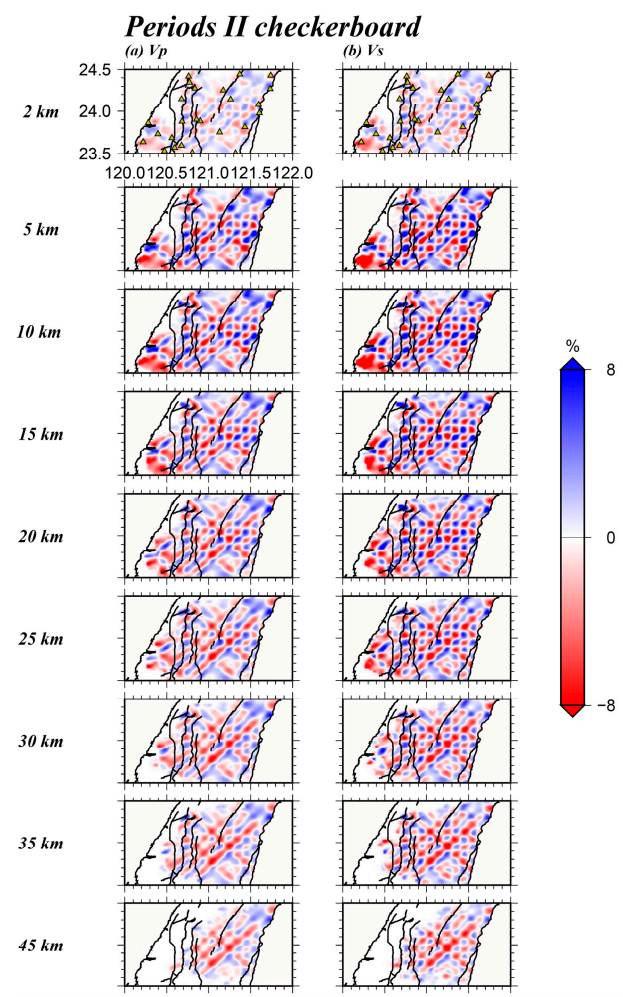

Figure 3. Perturbations of $\pm 8 \%$ of $\mathrm{Vp}$ and $\mathrm{Vs}$ were added to generate a new $3 \mathrm{D}$ velocity model in the form of a checkerboard (grid distance: $10 \times 10 \mathrm{~km}^{2}$ ). Yellow triangles represent the stations. (a) Period II checkerboard of Vp. (b) Period II checkerboard of Vs.

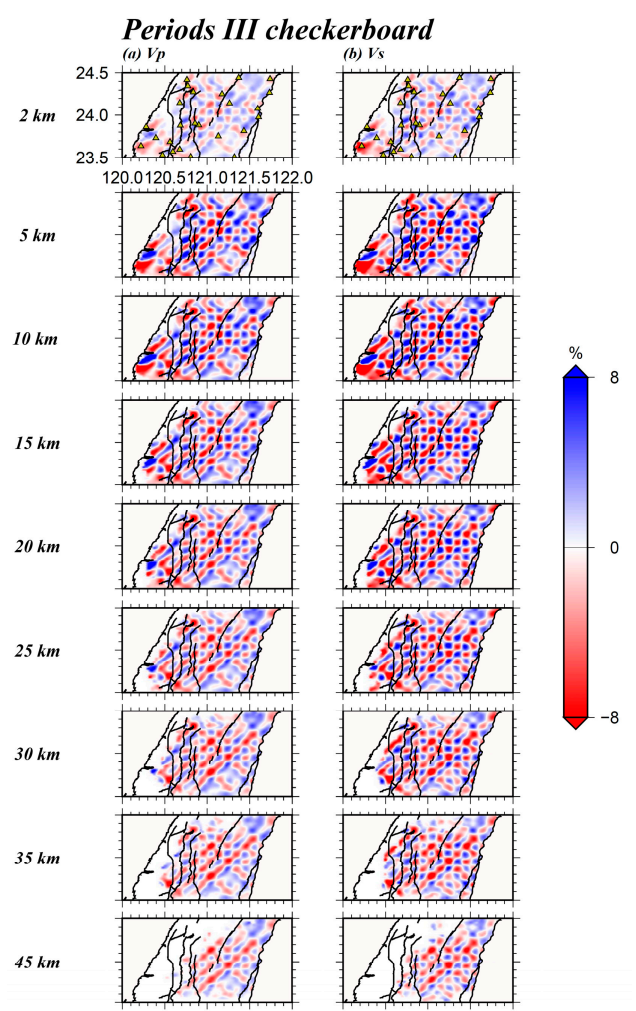

Figure 4. Perturbations of $\pm 8 \%$ of $\mathrm{Vp}$ and Vs were added to generate a new 3D velocity model in the form of a checkerboard (grid distance: $10 \times 10 \mathrm{~km}^{2}$ ). Yellow triangles represent the stations. (a) Period III checkerboard of Vp. (b) Period III checkerboard of Vs. 


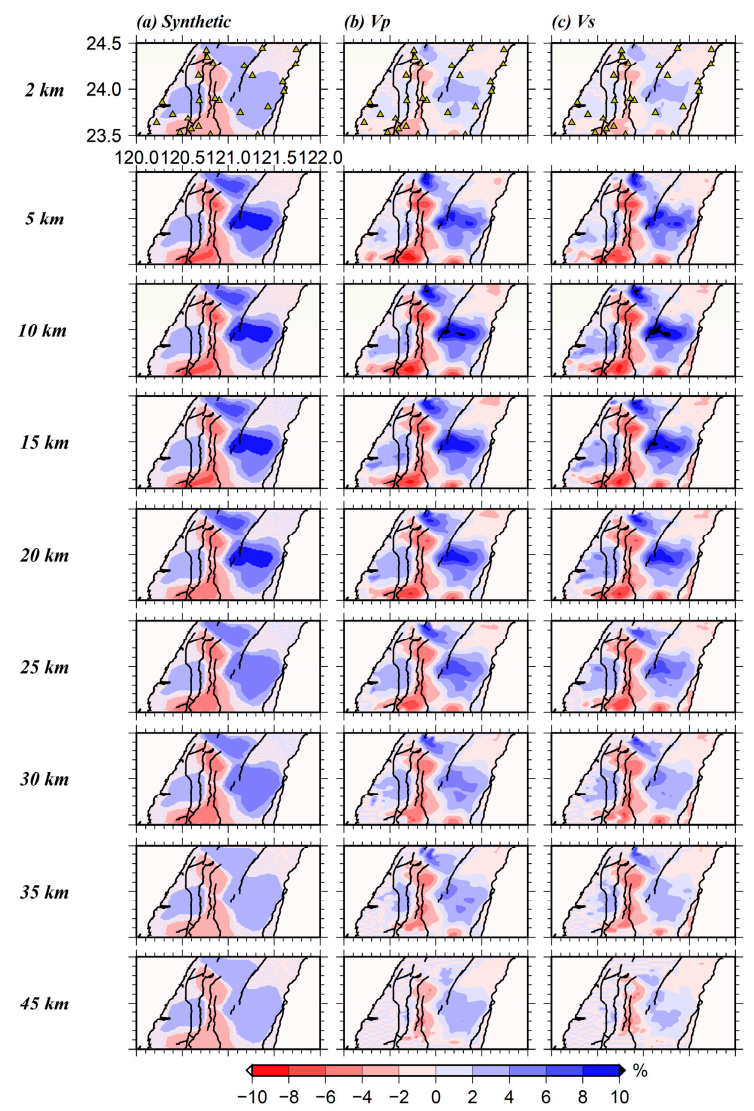

Figure 5. (a) A synthetic model with realistic configurations of anomalies. (b) Period I synthetic model of Vp. (c) Period I synthetic model of Vs. See the detail description in the text.

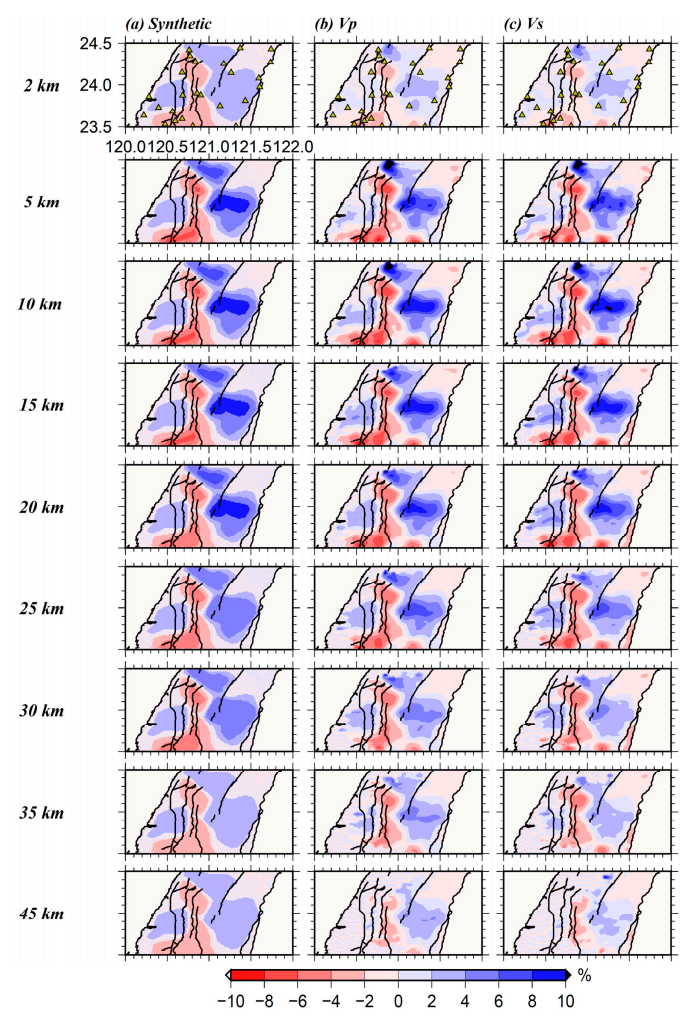

Figure 6. (a) A synthetic model with realistic configurations of anomalies. (b) Period II synthetic model of Vp. (c) Period II synthetic model of Vs. See the detail description in the text. 


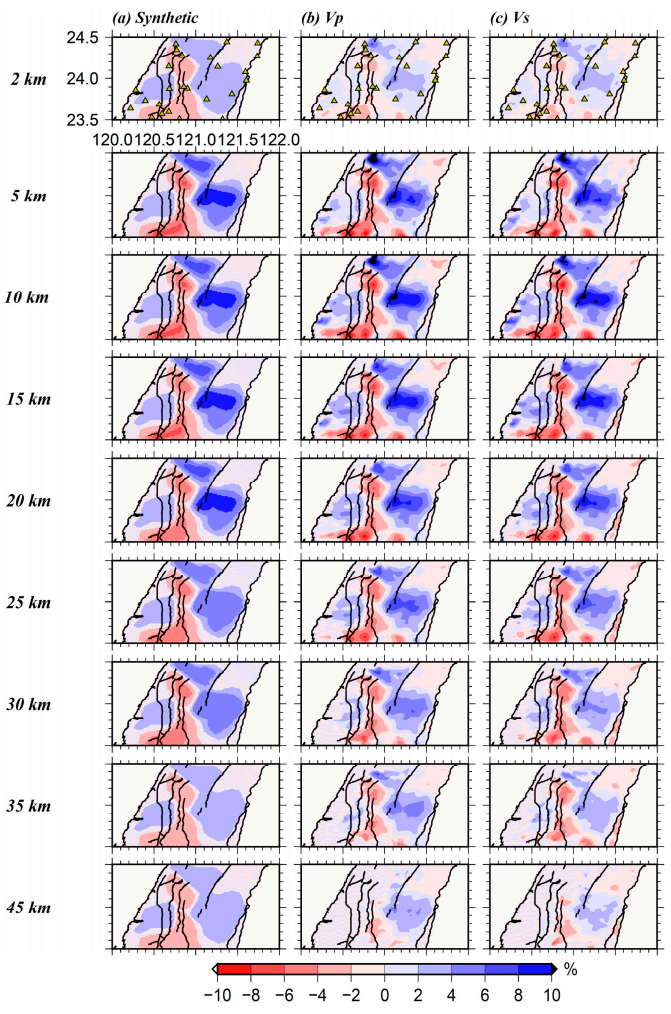

Figure 7. (a) A synthetic model with realistic configurations of anomalies. (b) Period III synthetic model of Vp. (c) Period III synthetic model of Vs. See the detail description in the text.

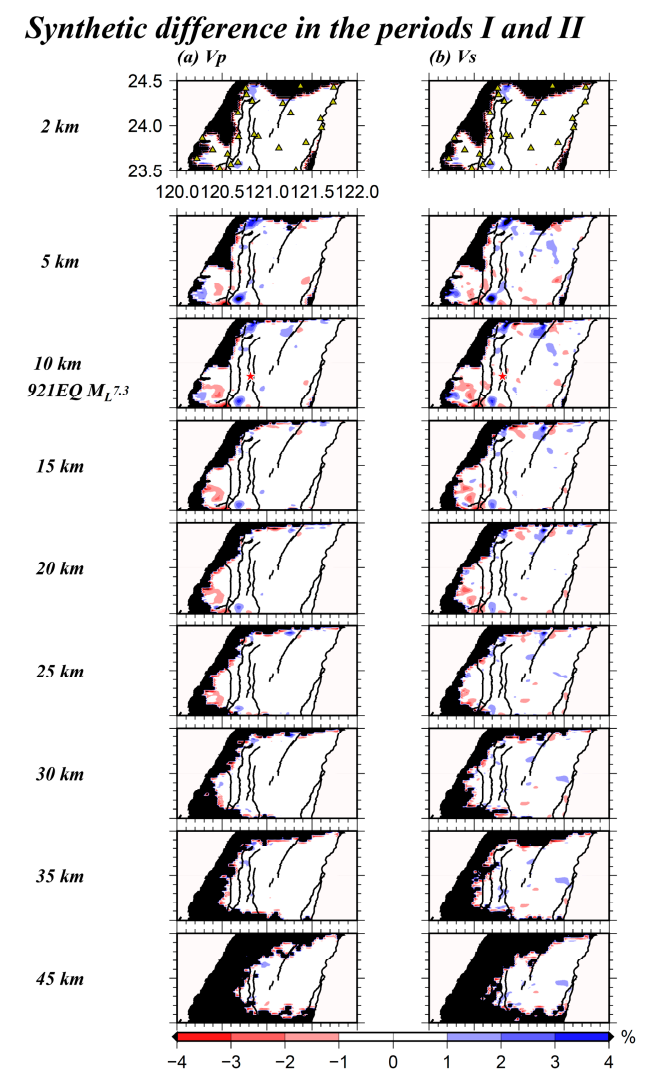

Figure 8. The synthetic difference model with unchanged synthetic model recovered using two data subsets. Yellow triangles represent the stations. (a) Synthetic difference of Vp in the periods I and II. (b) Synthetic difference of Vs in the periods I and II. 
The grid settings for the two cases were the same. After restoring models in these two time periods, we computed the differences between the recovered models, representing the Vp and Vs variations, at different depths. First, Figure $8 \mathrm{a}, \mathrm{b}$, respectively, show that the $\mathrm{Vp}$ and $\mathrm{Vs}$ results are similar, except for the border area, where the variation was $4 \%$. In other areas, the variations were less than $0.40 \%$ and $0.54 \%$ on average. Next, Figure 9a,b, respectively, show that the Vp and Vs results are similar, except for the border area, where the variation was $4 \%$. In other areas, the variations were less than $0.54 \%$ and $0.64 \%$ on average.

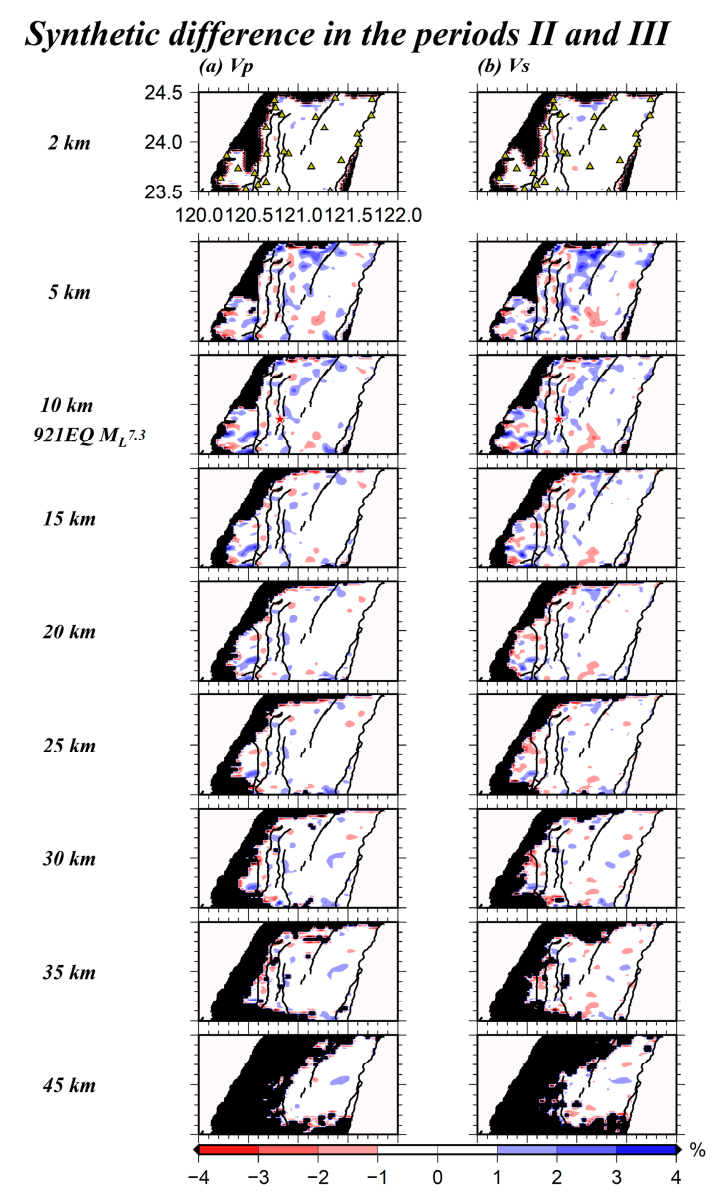

Figure 9. The synthetic difference model with unchanged synthetic model recovered using two data subsets. Yellow triangles represent the stations. (a) Synthetic difference of Vp in the periods II and III. (b) Synthetic difference of Vs in the periods II and III.

We set the white area as resolvable, where the average variation was less than the actual temporal evolution of the velocity structure. These results revealed that the change over time was reliable. The blue and red areas represented greater variation, which implies greater effect of artifacts. In contrast, no temporal resolution capability could be shown in the black area. Furthermore, the variation in the synthetic models in periods II and III (Figure 9) was similar to that in periods I and II (Figure 8). However, the variations in Vp and Vs increase, which is attributed to the aftershocks of the Chi-Chi earthquake. Therefore, special attention must be given to the subsequent interpretation of the results.

As will be explained in the following section, the seismic velocity variations obtained by the model were less than those obtained from actual observation in the data analysis. This implies that the temporal variation in our model is not significantly affected by the artifacts associated with changes in the ray configuration for the selected data subset. However, a much wider range of artifact effects must be considered when exploring local changes in the study area. The presented test results demonstrate that, for the study region, 
the proposed model robustly revealed the variations in the crust with a scale of more than $2 \%$. The results of the experimental data analysis for stronger variations, presented in the next section, thus represent variations that occur in the crust as a result of tectonic processes.

\section{Results and Discussion}

\subsection{Temporal Evolution of a Velocity Structure}

The pore pressure is inversely proportional to the seismic wave velocity, evidenced by oil field detection and laboratory experiments [39]. Moreover, many experiments have examined the effects of fluid-filled cracks on seismic velocity [40-43]. Therefore, it is generally accepted that $\mathrm{Vp}$ is inversely proportional to the crack density and that $\mathrm{Vp} / \mathrm{Vs}$ is proportional to the fluid saturation in the crack. In addition, its correlation with the rock crack and pore pressure was discussed. Fortunately, there have been studies using more realistic observational data to build fracture models [44] and there are detailed discussions on the differences between various fracture models.

First, variations in Vp, Vs, and Vp/Vs in the $\alpha$ zone (source area, see Figure 10b) before the occurrence of the Chi-Chi earthquake sequence in periods I and II are discussed and are shown in Figure 10.

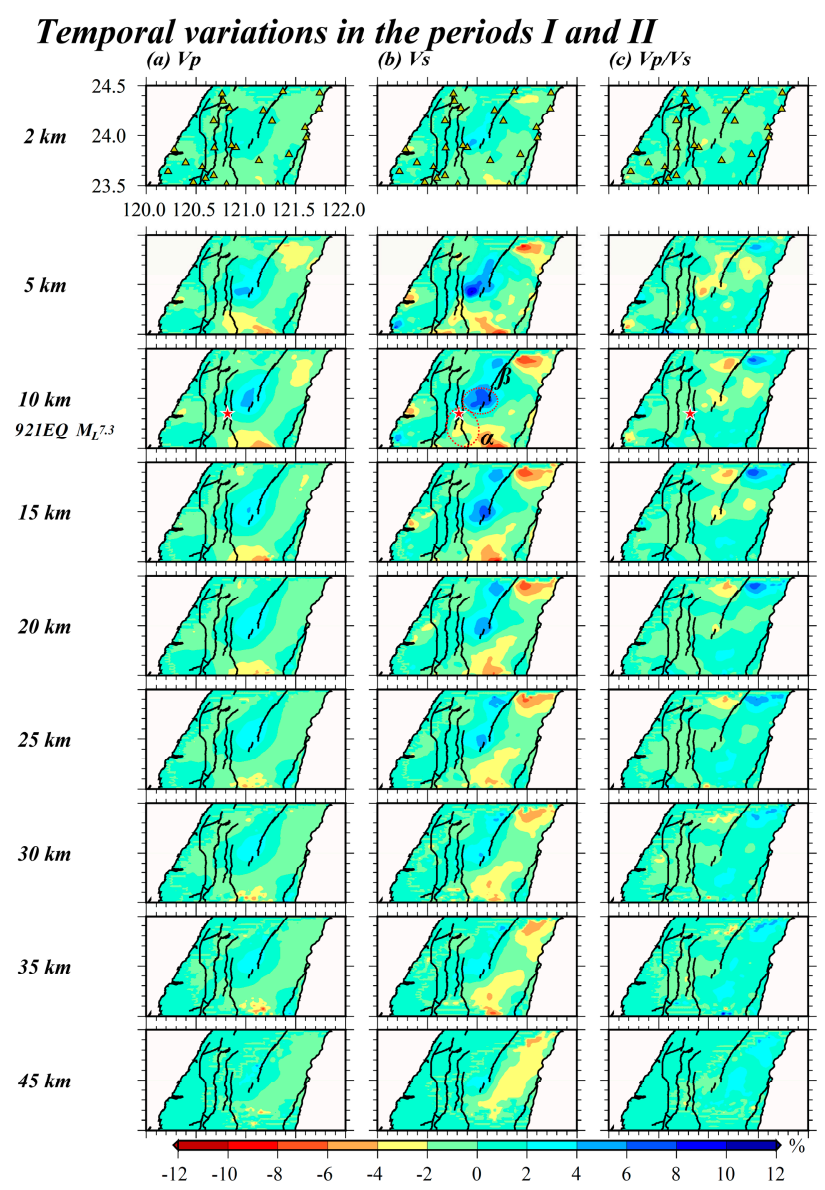

Figure 10. (a) Temporal variation in Vp in the periods I and II. (b) Temporal variation in Vs in the periods I and II. (c) Temporal variation in $\mathrm{Vp} / \mathrm{Vs}$ in the periods I and II. See the detail description in the text.

The results indicate that $\mathrm{Vp}$ decreased by approximately $2 \%$, Vs decreased by approximately $4 \%$, and $\mathrm{Vp} / \mathrm{Vs}$ increased by approximately $4 \%$. In the $\beta$ zone (around the source area, see Figure 10b), Vp increased by approximately $4 \%$, Vs increased by approximately $10 \%$, and $\mathrm{Vp} / \mathrm{Vs}$ decreased by approximately $6 \%$. The results demonstrate that the 
subsurface structure had already changed before the impending Chi-Chi earthquake, and the reason for the significant decrease in $\mathrm{Vs}$ in the $\alpha$ zone compared with $\mathrm{Vp}$ is possibly the proliferation of cracks and fluid intrusion. The authors of [45] also speculated using a magnetotelluric technique that the seismogenic mechanism of the Chi-Chi earthquake may be associated with fluid intrusion. The velocity structure variation in the $\beta$ zone was opposite to that in the $\alpha$ zone, presumably due to the closure of the crack, resulting in an increase in Vs. Figure 10b,c clearly show that, at depths of 5-10 km, the hypocenter of the Chi-Chi earthquake occurred in the boundaries of the areas of high and low Vp/Vs. However, no significant difference was noticed at depths greater than $15 \mathrm{~km}$.

From periods II and III, the variations in Vp, Vs, and Vp/Vs after the earthquake sequence are shown in Figure 11.

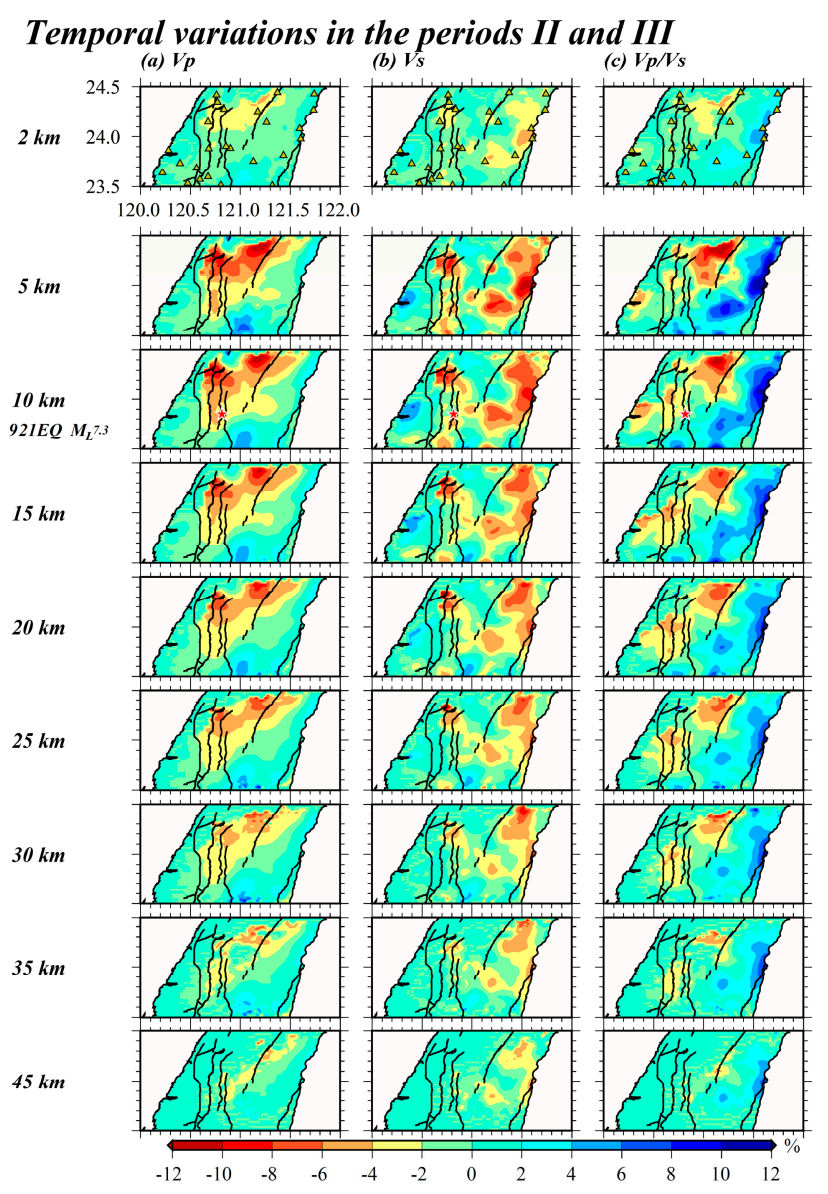

Figure 11. (a) Temporal variation in Vp in the periods II and III. (b) Temporal variation in Vs in the periods II and III. (c) Temporal variation in Vp/Vs in the periods II and III. See the detail description in the text.

The results demonstrate that $\mathrm{Vp}$ and Vs varied within $\pm 10 \%$ in the vicinity of the CLF. These variations were more complicated in the shallow crust (equal to or less than $15 \mathrm{~km}$ ). Note that in Figure 11a, the result shows a significant decrease in Vp at a depth of 5-15 km in the northern segment of the CLF. The distribution of the low Vp anomaly is in good agreement with the result of maximum slip distribution in the GPS calculation [46,47], because the slip vector in the GPS calculation is the combined effect from the surface observation. However, from the temporal variations in the velocity structure, we can estimate the possible slip pattern beneath the subsurface. When the depth was less than $15 \mathrm{~km}$, the lateral variation in $\mathrm{Vp}$ was more prominent than in the lower crust, which reflected changes in rock cracks after the earthquake occurred. No more lateral change was noted for depths greater than $25 \mathrm{~km}$, which indicated that the lower crust was less 
affected by the Chi-Chi earthquake. At a depth of more than $15 \mathrm{~km}$, the variations in Vs and $\mathrm{Vp} / \mathrm{Vs}$ near the hypocenter reduced after the earthquake, and the area with obvious velocity variation was located in the area north of the CLF to LF.

\subsection{Tectonic Implications}

In this study, we discussed the relationship between the velocity structures of Vs and $\mathrm{Vp} / \mathrm{Vs}$ over time and the geometry of faults in order to determine the variations in Vs and $\mathrm{Vp} / \mathrm{Vs}$ before and after the occurrence of the Chi-Chi earthquake sequences along the velocity profiles. Figure 12 shows the time-dependent perturbation profile in periods I and II. It can be seen from the section of $\mathrm{CC}^{*}-\mathrm{EE}^{*}$ connection that in the $\alpha$ area (hypocenter) during the Chi-Chi earthquake, Vp/Vs increased by approximately $4 \%$ and Vs decreased by approximately $4 \%$.

(a) Temporal variations profile of Vs in the periods I and II

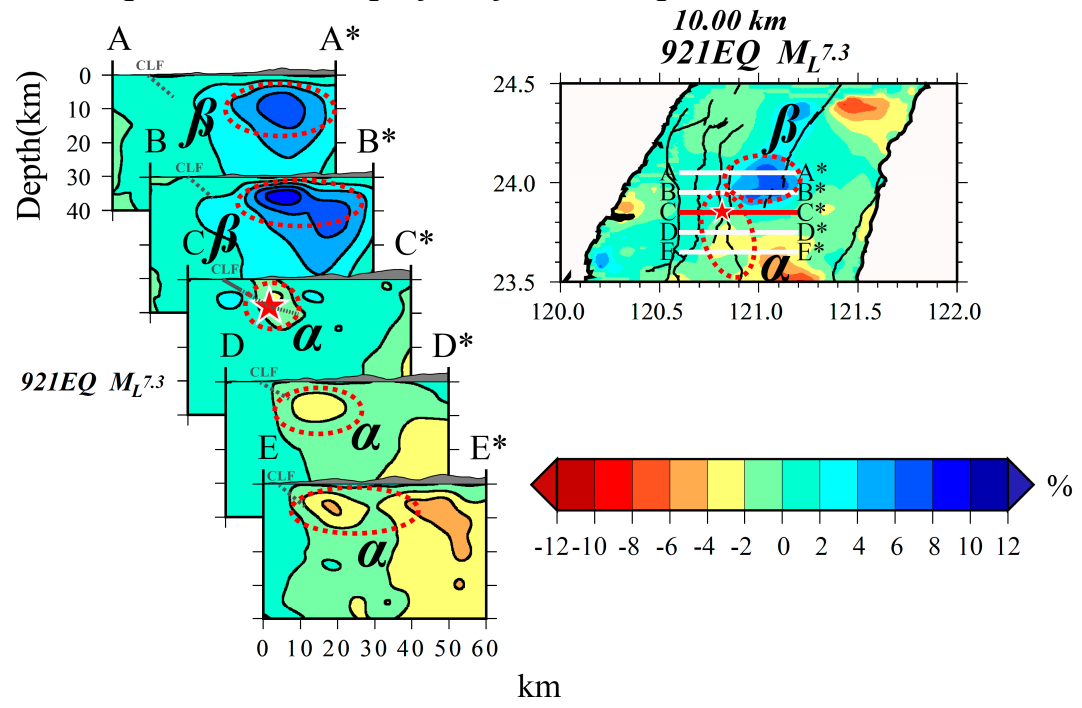

(b) Temporal variations profile of $V p / V s$ in the periods I and II

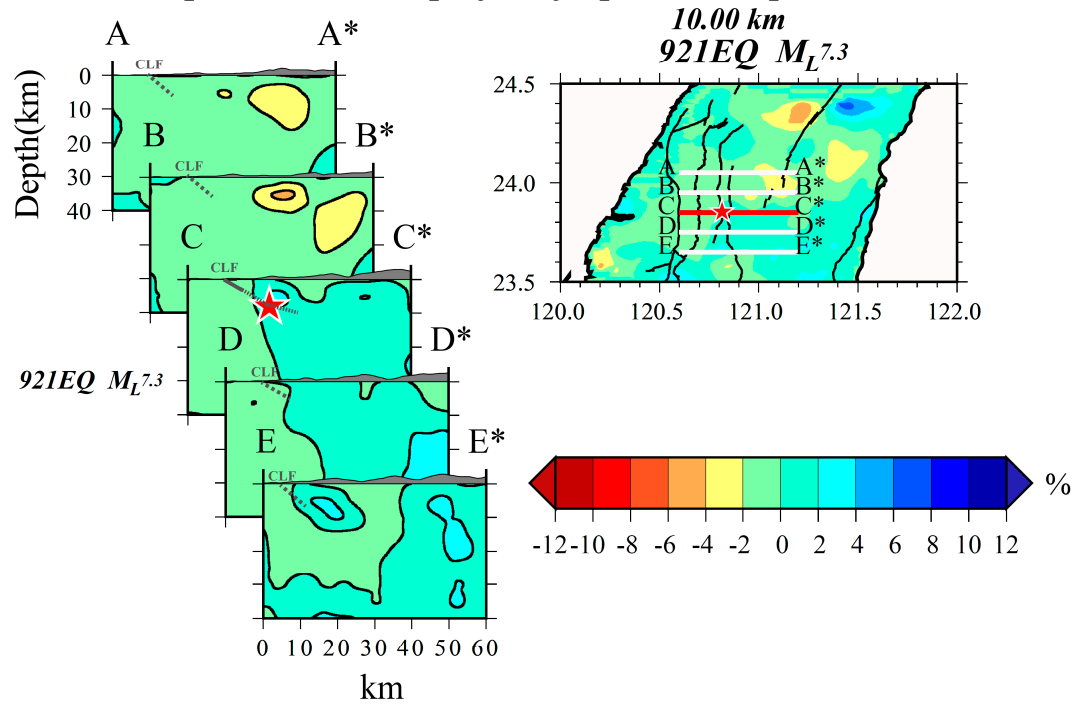

Figure 12. The $\mathrm{AA}^{*}$ to $\mathrm{EE}^{*}$ profiles analyzed in this study are displayed in the left panel. The profile across the Chi-Chi earthquake uses gray dotted line and red star to indicate the location of the CLF and the mainshock, respectively. The right panel shows the location of the $\mathrm{AA}^{*}$ to $\mathrm{EE}^{*}$ profiles. The profile CC* across the Chi-Chi earthquake are depicted with the thick red line. (a) Temporal variation profile of Vs in the periods I and II. (b) Temporal variation profile of Vp/Vs in the periods I and II. 
In the $\beta$ area (near the hypocenter), $\mathrm{Vp} / \mathrm{Vs}$ decreased by approximately $6 \%$ and $\mathrm{Vs}$ increased by approximately $10 \%$. The fluid-filled fractured region at the $\alpha$ area (hypocenter) was assumed to lead to fissure expansion; therefore, the decline of Vs was greater than Vp. Furthermore, in the south to north sections of Vs, Vs changed along an eastwardtilted inclined plane. Moreover, Vs changed more significantly south of the hypocenter compared with the north. This phenomenon occurred before the Chi-Chi earthquake and was concentrated south of the CLF. However, the variations in the $\beta$ area were opposite to those in the $\alpha$ area.

In contrast, in this study, we discuss the velocity variation over a long time scale before the occurrence of the earthquake sequence; we found remarkable changes in periods I and II, such as the decrease in Vs in the $\alpha$ region and the increase in Vs in the $\beta$ region, while the hypocenter was located at the junction of the $\alpha$ and $\beta$ areas. This phenomenon indicated that the direction of the tectonic stress was from the south-east (approximately $\left.100^{\circ},[48]\right)$, resulting in the closure of the pores in the $\beta$ area, which may allow the fluid to migrate toward the $\alpha$ area. The decrease in the frictional strength of the fault in this area might be attributed to the vicinity of the $\alpha$ area to the hypocenter, the increase in the pore density, and the possibility of fluid intrusion. These factors may have led to the occurrence of the Chi-Chi earthquake, suggesting it is a precursor phenomenon.

From periods II and III, the time-dependent perturbation profile of Vs is shown in Figure 13; it can be seen from the section of $\mathrm{AA}^{*}-\mathrm{EE}^{*}$ connection in the low anomalous regions that Vs significantly expanded from south to north, revealing that the northern section of the CLF has a larger slip displacement after the rupture, which leads to an east-dipping, low-Vs anomalous region.

Furthermore, the slip displacement of the southern section was smaller than that of the northern section, and $\mathrm{Vp} / \mathrm{Vs}$ exhibited fewer anomalies compared with those in the northern section. This anomalous region is speculated to be the Chi-Chi earthquake rupture zone, which is consistent with the location of the CLF. Further analysis is required to explore the spatial variation of the earthquake rupture, the results of which would also be valuable for confirming the larger rupture zone in the northern section of the CLF compared to the southern section.

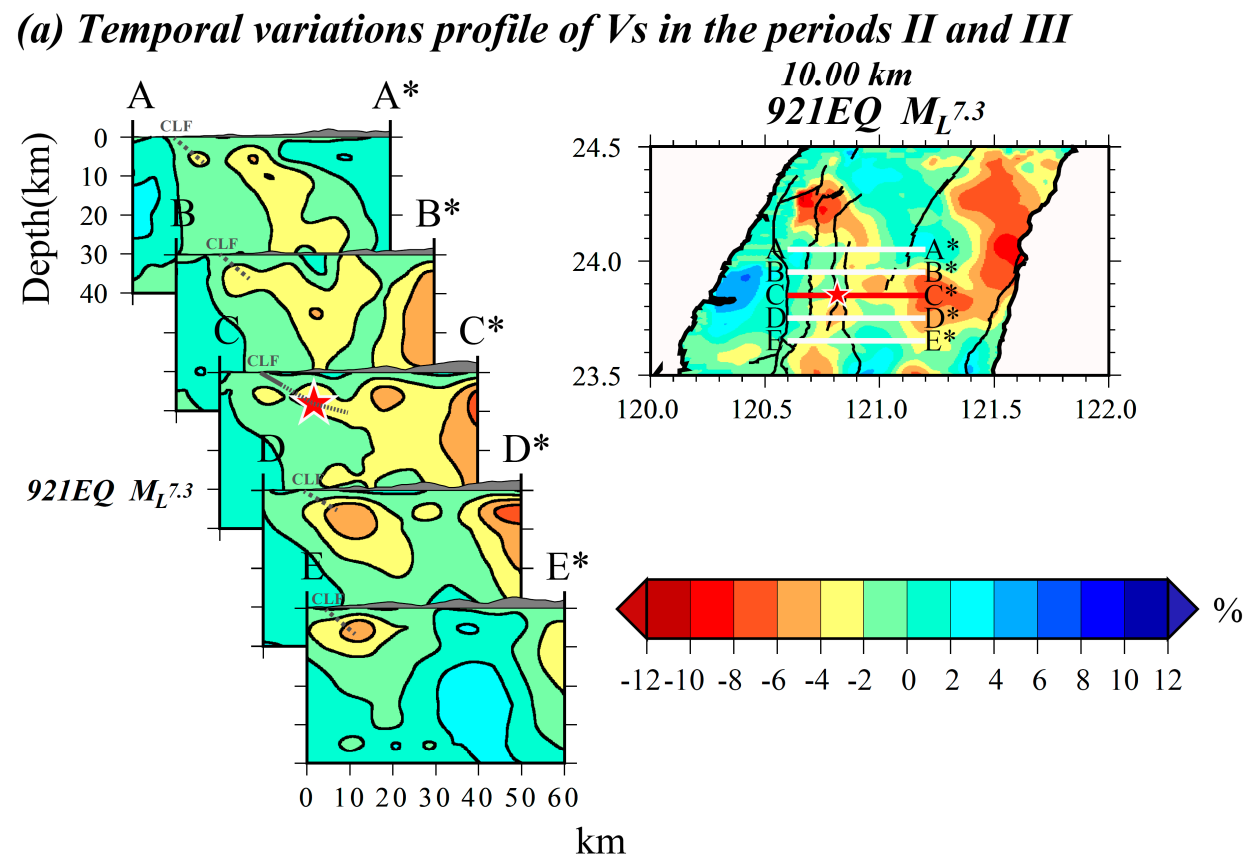

Figure 13. Cont. 
(b) Temporal variations profile of $\mathrm{Vp} / \mathrm{V}$ s in the periods II and III

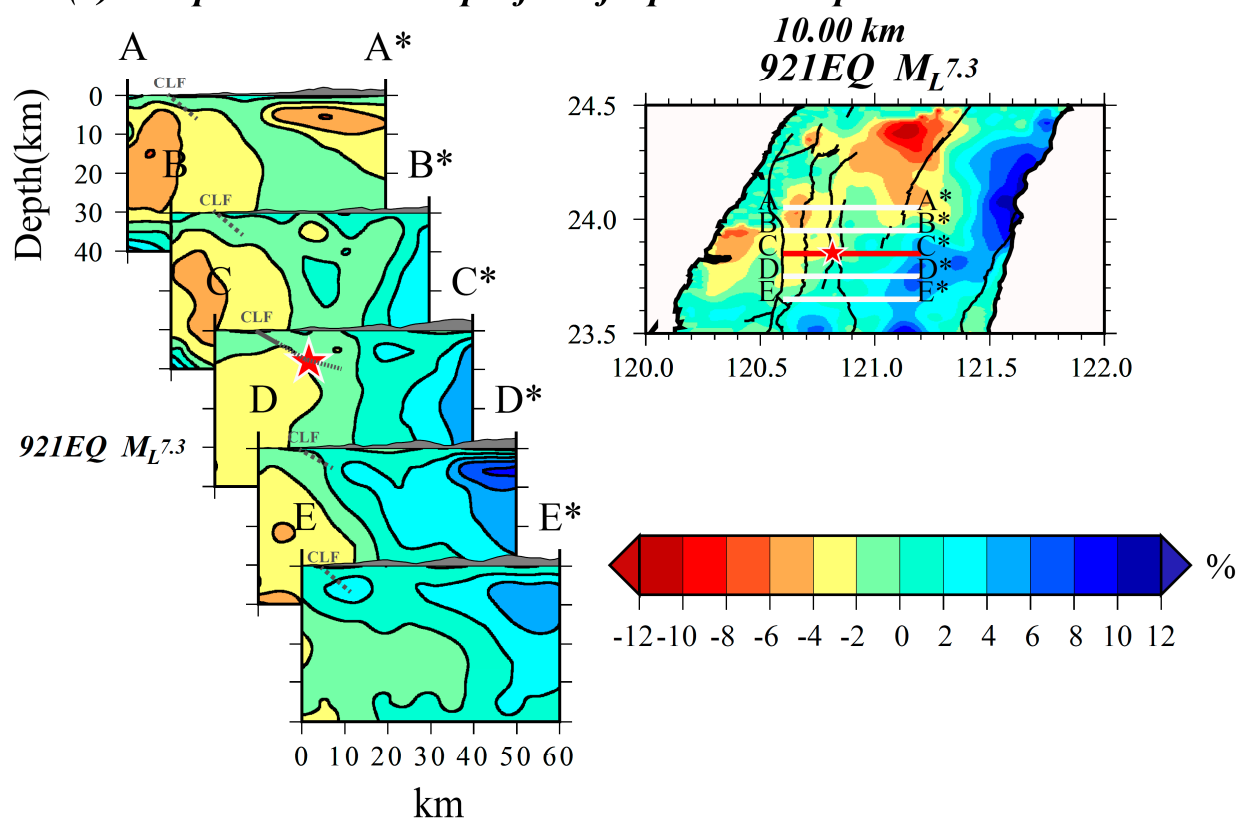

Figure 13. The $\mathrm{AA}^{*}$ to $\mathrm{EE}^{*}$ profiles analyzed in this study are displayed in the left panel. The profile across the Chi-Chi earthquake uses gray dotted line and red star to indicate the location of the CLF and the mainshock, respectively. The right panel shows the location of the $\mathrm{AA}^{*}$ to $\mathrm{EE}^{*}$ profiles. The profile $\mathrm{CC}^{*}$ across the Chi-Chi earthquake are depicted with the thick red line. (a) Temporal variation profile of Vs in the periods II and III. (b) Temporal variation profile of Vp/Vs in the periods II and III.

In addition, the authors of [49] independently analyzed the Qs of earthquakes and found that Qs changed with time. Among them, the region where Qs is higher before the Chi-Chi earthquake corresponds to the $\beta$ region where Vs is increased in Figure 12a of the present study. The lower area of Qs after the Chi-Chi earthquake is corresponding to the Vs falling area in Figure 13a of this study. They speculate that the decrease in Qs (increased S-wave attenuation) may indicate an increase in fluid content in the ruptured area after the Chi-Chi earthquake which resulting in increased pore fluid saturation.

\section{Conclusions}

This research used travel time data for earthquake events compiled by the Central Weather Bureau Seismic Network (CWBSN). Using these data, tomography inversion was conducted for different periods of structures in central Taiwan. The results were utilized to deduce the relationship between seismicity and fault structure with spatiotemporal evolution. Based on the aforementioned information, the following conclusions can be drawn.

1. The results showed that the temporal variations of $\mathrm{Vp}$ were less than those of $\mathrm{Vs}$, and $\mathrm{Vp}$ was not affected significantly before the occurrence of the Chi-Chi earthquake.

2. The velocity profile indicates that the temporal variation of the subsurface velocity structure may have been affected before the occurrence of the Chi-Chi earthquake sequences. In the $\alpha$ area, the decreased Vs and increased pore pressure are attributed to the increasing density of microcracks and the possibility of fluid or gas intrusion. Moreover, we observed increasing Vs in the $\beta$ area; this was because the $\beta$ area was located on the eastern side of the $\alpha$ area. It was presumed that the direction of the tectonic stress was from the southeast, resulting in the closure of the pores and fluid migration in the $\beta$ area. This phenomenon may be attributed to the different mechanism of action in the $\alpha$ and $\beta$ areas. 
3. Based on the present results, the temporal variations reflect precursory phenomena in the source area before the Chi-Chi earthquake and the range of the CLF affected by the Chi-Chi earthquake.

Author Contributions: Conceptualization, C.-F.L., S.W. and C.-H.C.; methodology, C.-F.L. and S.W.; software, C.-F.L.; validation, C.-F.L. and S.W.; formal analysis, C.-F.L.; investigation, C.-F.L. and S.W.; resources, S.W., C.-H.C. and Y.-N.C.; data curation, C.-F.L. and S.W.; writing-original draft preparation, C.-F.L.; writing-review and editing, C.-F.L. and S.W.; visualization, C.-F.L.; supervision, S.W., C.-H.C. and Y.-N.C.; project administration, S.W., C.-H.C. and Y.-N.C.; funding acquisition, S.W., C.-H.C. and Y.-N.C. All authors have read and agreed to the published version of the manuscript.

Funding: This research was funded by the Taiwan Ministry of Science and Technology, grant number MOST 110-2116-M-194 -004.

Data Availability Statement: We are grateful to CWBSN (http://gdms.cwb.gov.tw/index.php, accessed on 22 August 2021) for providing P- and S-arrival-time data.

Acknowledgments: We are grateful to CWBSN (http://gdms.cwb.gov.tw/index.php, accessed on 22 August 2021) for providing P- and S-arrival-time data. This research is supported by the Taiwan Ministry of Science and Technology. We thanks for editor and reviewer's comments to improve the quality of the MS.

Conflicts of Interest: The authors declare no conflict of interest.

\section{Appendix A}

Results of velocity structure model

In general, the seismic velocity is affected by several geological factors, including lithology, fluid saturation, pore density, geometry of the crack, and the degree and type of rock cementation [50]. The effect of shallow layer is the most prominent; the pressure increases with depth due to the weight of the rocks above the layer, which subsequently leads to the closure of the majority of the pores [51].

This study was divided into three time periods to explore the variations in Vp, Vs, and $\mathrm{Vp} / \mathrm{Vs}$ in the study area; the results are shown in Figures A1-A3. We divided the time period 1 January 1991-31 December 2003 into three periods to study the change in the velocity structure before and after the Chi-Chi earthquake that occurred on 21 September 1999 (UTC+8). Each period is discussed in the following paragraphs.

In the period I (1 January 1991-31 December 1995), the lateral variations in Vp (Figure A1a), Vs (Figure A1b), and Vp/Vs (Figure A1c) in the study area were not significantly different from those at depth. However, at a depth of 10-45 km, especially at a depth of $15 \mathrm{~km}$ or less, the Hsuehshan Range presented a significantly low Vp and Vs zone, which may be related to the plastic deformation caused by the plate extrusion (plate collision); these findings were consistent with the previous studies [15-18]. In addition, there was a higher in Vs and a lower in Vp/Vs at depths of 5-20 km in the LF and LVF.

In the period II (1 January 1996-19 September 1999), which was before the occurrence of the Chi-Chi earthquake sequence, Vp (Figure A2a) showed no significant variation compared to that in the first period. However, Vs (Figure A2b) began to change significantly before the earthquake. We found that there was lower Vs value in the source area, resulting in a higher $\mathrm{Vp} / \mathrm{Vs}$; this may be due to the cracks generated in this area and the intrusion of the fluid causing pore expansion. Instead, Vs was higher around the source area, which led to a lower $\mathrm{Vp} / \mathrm{Vs}$. This may be attributed to the closure of the pores in this region. At depths of $15-35 \mathrm{~km}$, the low-Vs zone in the WF was still visible.

In the period III (1 January 2001-31 December 2003), Vp (Figure A3a), Vs (Figure A3b), and $\mathrm{Vp} / \mathrm{Vs}$ (Figure A3c) were recorded after the episode of the Chi-Chi earthquake sequence. The results showed significant lateral variations at depths less than $15 \mathrm{~km}$, and the tectonic stress was assumed to be readjusted after the large earthquake. One interesting phenomenon at depths of 5-25 km was the lower Vp anomaly in the northern and WF and HR compared to that in the first and second periods. Furthermore, the abnormal range of $\mathrm{Vp}$ was larger than the range in Vs. At a depth of $5 \mathrm{~km}$, relatively low Vp/Vs 
was concentrated in the CLF. A high Vp/Vs mainly concentrated in the south and north sides. At a depth of $10 \mathrm{~km}$, relatively low $\mathrm{Vp} / \mathrm{Vs}$ was observed westward and concentrated between the CHF and SKF; moreover, the range of the low $\mathrm{Vp} / \mathrm{Vs}$ tended to expand. The low $\mathrm{Vp} / \mathrm{Vs}$ was located further to the central of the LF at depths of 5-20 km. The high $\mathrm{Vp} / \mathrm{Vs}$ was located further to the south side of the CLF and north side of the LVF at depths of $5-35 \mathrm{~km}$.

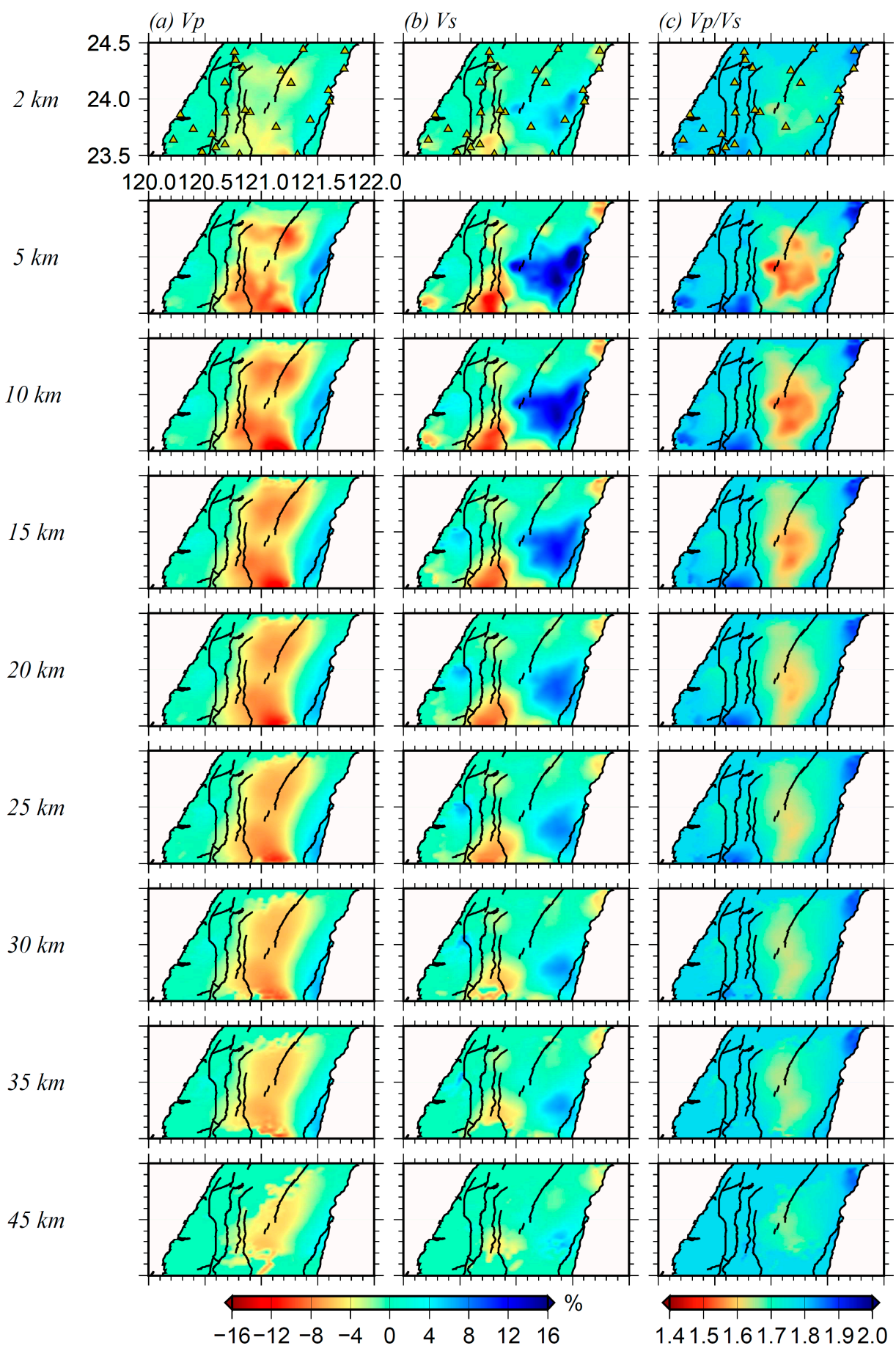

Figure A1. This study is divided into three periods to explore the $\mathrm{Vp}, \mathrm{Vs}$, and $\mathrm{Vp} / \mathrm{Vs}$ in the study area. Yellow triangle represents the station. The results of Figure A1 represent the first period. (a) Vp at different depths. (b) Vs at different depths. (c) Vp/Vs at different depths. 


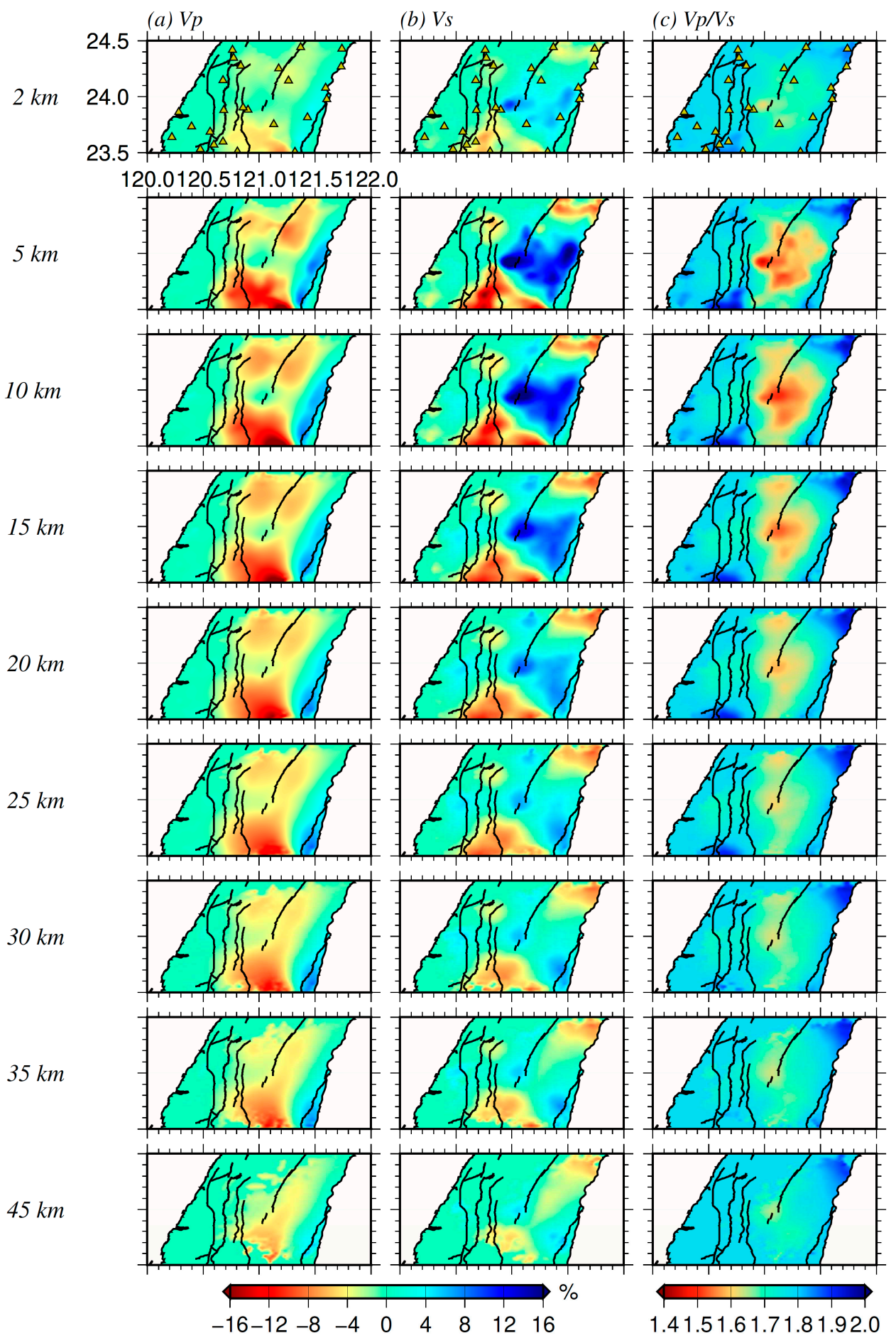

Figure A2. This study is divided into three periods to explore the $\mathrm{Vp}, \mathrm{Vs}$, and $\mathrm{Vp} / \mathrm{Vs}$ in the study area. Yellow triangle represents the station. The results of Figure A2 represent the second period. (a) Vp at different depths. (b) Vs at different depths. (c) Vp/Vs at different depths. 


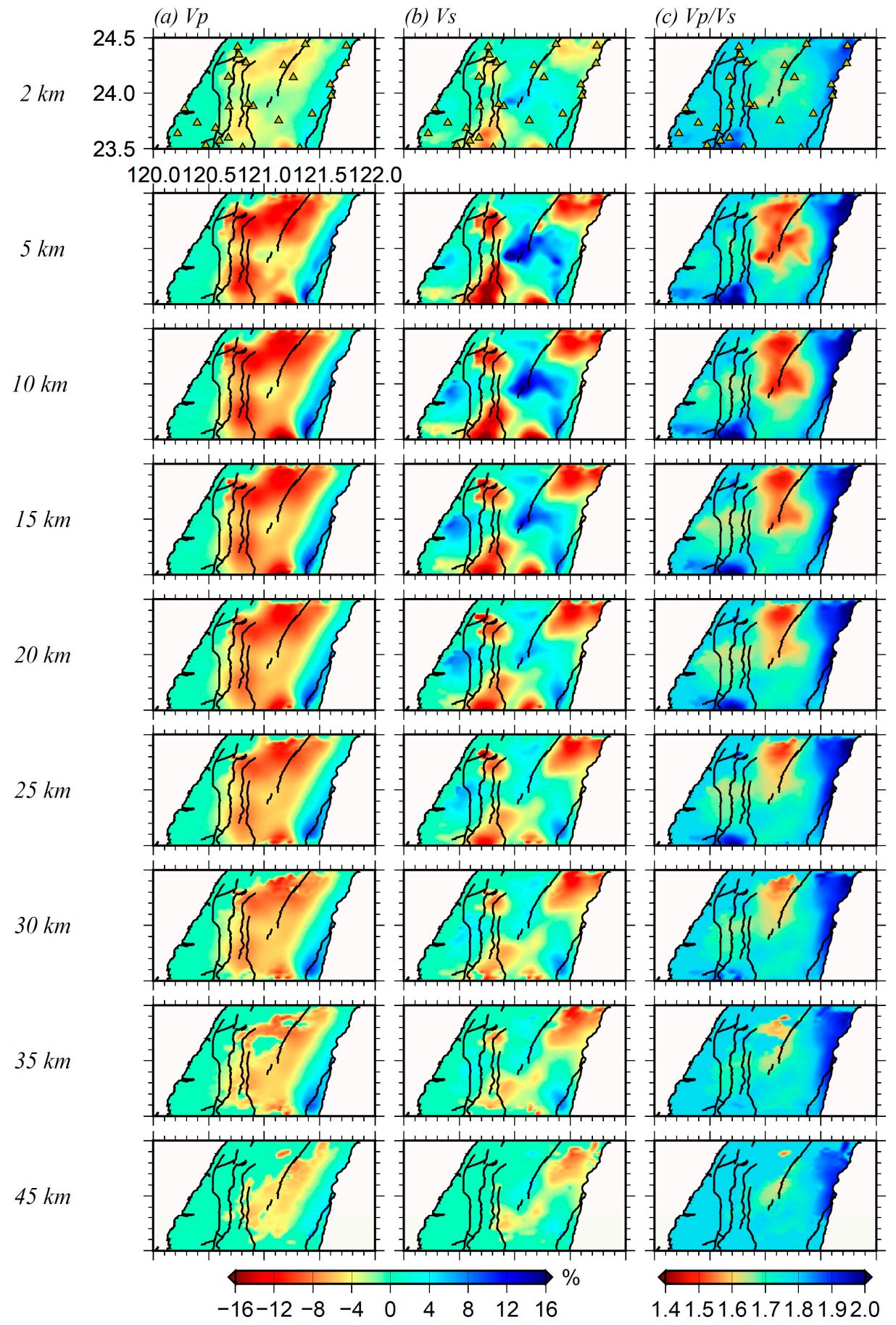

Figure A3. This study is divided into three periods to explore the $\mathrm{Vp}, \mathrm{Vs}$, and $\mathrm{Vp} / \mathrm{Vs}$ in the study area. Yellow triangle represents the station. The results of Figure A3 represent the third period. (a) Vp at different depths. (b) Vs at different depths. (c) Vp/Vs at different depths.

\section{References}

1. Liu, J.Y.; Chen, Y.I.; Chuo, Y.J.; Tsai, H.F. Variations of ionospheric total electron content during the Chi-Chi Earthquake. Geophys. Res. Lett. 2001, 28, 1383-1386. [CrossRef]

2. Akhoondzadeh, M. Genetic algorithm for TEC seismo-ionospheric anomalies detection around the time of the Solomon $(\mathrm{Mw}=8.0)$ earthquake of 06 February 2013. Adv. Space Res. 2013, 52, 581-590. [CrossRef] 
3. Melgarejo-Morales, A.; Vazquez-Becerra, G.E.; Millan-Almaraz, J.R.; Pérez-Enríquez, R.; Félix, C.A.M.; Gaxiola-Camacho, J.R. Examination of seismo-ionospheric anomalies before earthquakes of Mw $\geq 5.1$ for the period 2008-2015 in Oaxaca, Mexico using GPS-TEC. Acta Geophys. 2020, 68, 1-16. [CrossRef]

4. Wu, Y.-M.; Chen, C.-C. Seismic reversal pattern for the 1999 Chi-Chi, Taiwan, MW 7.6 earthquake. Tectonophysics 2007, 429, 125-132. [CrossRef]

5. Asim, K.M.; Martínez-Álvarez, F.; Basit, A.; Iqbal, T. Earthquake magnitude prediction in Hindukush region using machine learning techniques. Nat. Hazards 2016, 85, 471-486. [CrossRef]

6. Chen, C.-H.; Wang, W.-H.; Teng, T.-L. 3D Velocity Structure around the Source Area of the 1999 Chi-Chi, Taiwan, Earthquake: Before and After the Mainshock. Bull. Seism. Soc. Am. 2004, 91, 1013-1027. [CrossRef]

7. Walck, M.C. Three-dimensionalVp/Vsvariations for the Coso Region, California. J. Geophys. Res. Space Phys. 1988, 93, 2047. [CrossRef]

8. Michelini, A.; McEvilly, T. Seismological studies at Parkfield. I. Simultaneous inversion for velocity structure and hypocenters using cubic B-splines parameterization. Bull. Seismol. Soc. Am. 1991, 81, 524-552.

9. Miller, S.A. Fluid-mediated influence of adjacent thrusting on the seismic cycle at Parkfield. Nature 1996, 382, 799-802. [CrossRef]

10. Li, Y.-G.; Chen, P.; Cochran, E.S.; Vidale, J.E. Seismic velocity variations on the San Andreas fault caused by the 2004 M6 Parkfield Earthquake and their implications. Earth Planets Space 2007, 59, 21-31. [CrossRef]

11. Foulger, G.R.; Julian, B.R.; Pitt, A.M.; Hill, D.P.; Malin, P.E.; Shalev, E. Three-dimensional crustal structure of Long Valley caldera, California, and evidence for the migration of CO2under Mammoth Mountain. J. Geophys. Res. Space Phys. 2003, 108. [CrossRef]

12. Patane, D.; Barberi, G.; Cocina, O.; De Gori, P.; Chiarabba, C. Time-Resolved Seismic Tomography Detects Magma Intrusions at Mount Etna. Science 2006, 313, 821-823. [CrossRef] [PubMed]

13. Aggarwal, Y.P.; Sykes, L.R.; Armbruster, J.; Sbar, M.L. Premonitory Changes in Seismic Velocities and Prediction of Earthquakes. Nature 1973, 241, 101-104. [CrossRef]

14. Julian, B.R.; Foulger, G.R. Time-dependent seismic tomography. Geophys. J. Int. 2010, 182, 1327-1338. [CrossRef]

15. Kim, K.-H.; Chiu, J.-M.; Pujol, J.; Chen, K.-C.; Huang, B.-S.; Yeh, Y.-H.; Shen, P. Three-dimensional VP and VS structural models associated with the active subduction and collision tectonics in the Taiwan region. Geophys. J. Int. 2005, 162, 204-220. [CrossRef]

16. Wu, Y.-M.; Chang, C.-H.; Zhao, L.; Shyu, J.B.H.; Chen, Y.-G.; Sieh, K.; Avouac, J.-P. Seismic tomography of Taiwan: Improved constraints from a dense network of strong motion stations. J. Geophys. Res. Space Phys. 2007, 112. [CrossRef]

17. Kuo-Chen, H.; Wu, F.T.; Roecker, S.W. Three-dimensional P velocity structures of the lithosphere beneath Taiwan from the analysis of TAIGER and related seismic data sets. J. Geophys. Res. Space Phys. 2012, 117. [CrossRef]

18. Huang, H.-H.; Wu, Y.-M.; Song, X.; Chang, C.-H.; Lee, S.-J.; Chang, T.-M.; Hsieh, H.-H. Joint Vp and Vs tomography of Taiwan: Implications for subduction-collision orogeny. Earth Planet. Sci. Lett. 2014, 392, 177-191. [CrossRef]

19. Sibuet, J.-C.; Hsu, S.-K. How was Taiwan created? Tectonophysics 2004, 379, 159-181. [CrossRef]

20. Yu, S.-B.; Chen, H.-Y.; Kuo, L.-C. Velocity field of GPS stations in the Taiwan area. Tectonophysics 1997, 274, 41-59. [CrossRef]

21. Lin, A.T.; Watts, A.B.; Hesselbo, S.P. Cenozoic stratigraphy and subsidence history of the South China Sea margin in the Taiwan region. Basin Res. 2003, 15, 453-478. [CrossRef]

22. Teng, L.; Lin, A.T. Cenozoic tectonics of the China continental margin: Insights from Taiwan. Geol. Soc. London Spéc. Publ. 2004, 226, 313-332. [CrossRef]

23. Yang, K.-M.; Huang, S.-T.; Wu, J.-C.; Ting, H.-H.; Mei, W.-W. Review and New Insights on Foreland Tectonics in Western Taiwan. Int. Geol. Rev. 2006, 48, 910-941. [CrossRef]

24. Camanni, G.; Chen, C.-H.; Brown, D.; Alvarez-Marron, J.; Wu, Y.-M.; Chen, H.-A.; Huang, H.-H.; Chu, H.-T.; Chen, M.-M.; Chang, C.-H. Basin inversion in central Taiwan and its importance for seismic hazard. Geology 2014, 42, 147-150. [CrossRef]

25. Brown, D.; Alvarez-Marron, J.; Schimmel, M.; Wu, Y.-M.; Camanni, G. The structure and kinematics of the central Taiwan mountain belt derived from geological and seismicity data. Tectonics 2012, 31. [CrossRef]

26. Camanni, G.; Brown, D.; Alvarez-Marron, J.; Wu, Y.-M.; Chen, H.-A. The Shuilikeng fault in the central Taiwan mountain belt. J. Geol. Soc. 2014, 171, 117-130. [CrossRef]

27. Suppe, J. Mechanics of mountain building and metamorphism in Taiwan. Mem. Geol. Soc. China 1981, 4, 67-89.

28. Jackson, J.A. Reactivation of basement faults and crustal shortening in orogenic belts. Nature 1980, 283, 343-346. [CrossRef]

29. Poblet, J.; Lisle, R.J. Kinematic evolution and structural styles of fold-and-thrust belts. Geol. Soc. London Spéc. Publ. 2011, 349, 1-24. [CrossRef]

30. Okada, T.; Hasegawa, A.; Suganomata, J.; Umino, N.; Zhang, H.; Thurber, C.H. Imaging the heterogeneous source area of the 2003 M6.4 northern Miyagi earthquake, NE Japan, by double-difference tomography. Tectonophysics 2007, 430, 67-81. [CrossRef]

31. Sibson, R.H. Rupturing in overpressured crust during compressional inversion-the case from NE Honshu, Japan. Tectonophysics 2009, 473, 404-416. [CrossRef]

32. Koulakov, I.; Gladkov, V.; El Khrepy, S.; Al-Arifi, N.; Fathi, I.H. Application of repeated passive source travel time tomography to reveal weak velocity changes related to the 2011 Tohoku-Oki Mw 9.0 earthquake. J. Geophys. Res. Solid Earth 2016, 121, 4408-4426. [CrossRef]

33. Koulakov, I. LOTOS Code for Local Earthquake Tomographic Inversion: Benchmarks for Testing Tomographic Algorithms. Bull. Seism. Soc. Am. 2009, 99, 194-214. [CrossRef]

34. Um, J.; Thurber, C. A fast algorithm for two-point seismic ray tracing. Bull. Seismol. Soc. Am. 1987, 77, 972-986. [CrossRef] 
35. Koulakov, I.; Sobolev, S.V. A tomographic image of Indian lithosphere break-off beneath the Pamir-Hindukush region. Geophys. J. Int. 2006, 164, 425-440. [CrossRef]

36. Paige, C.C.; Saunders, M.A. LSQR: An Algorithm for Sparse Linear Equations and Sparse Least Squares. ACM Trans. Math. Softw. 1982, 8, 43-71. [CrossRef]

37. Van Der Sluis, A.; Van der Vorst, H. Numerical solution of large, sparse linear algebraic systems arising from tomographic problems. In Seismic Tomography; Springer: Berlin/Heidelberg, Germany, 1987; pp. 49-83. [CrossRef]

38. Koulakov, I.; Bohm, M.; Asch, G.; Lühr, B.-G.; Manzanares, A.; Brotopuspito, K.S.; Fauzi, P.; Purbawinata, M.A.; Puspito, N.T.; Ratdomopurbo, A.; et al. PandSvelocity structure of the crust and the upper mantle beneath central Java from local tomography inversion. J. Geophys. Res. Space Phys. 2007, 112. [CrossRef]

39. Jones, T.; Nur, A. Effect of temperature, pore fluids, and pressure on seismic wave velocity and attenuation in rock. In $S E G$ Technical Program Expanded Abstracts 1983; Society of Exploration Geophysicists: Tulsa, OK, USA, 1983; pp. $583-585$.

40. O'Connell, R.J.; Budiansky, B. Seismic velocities in dry and saturated cracked solids. J. Geophys. Res. Space Phys. 1974, 79, 5412-5426. [CrossRef]

41. Scholz, C.H. The Mechanics of Earthquakes and Faulting; Cambridge University Press: Cambridge, UK, 2019.

42. Sleep, N.H. Grain size and chemical controls on the ductile properties of mostly frictional faults at low-temperature hydrothermal conditions. Pure Appl. Geophys. 1994, 143, 41-60. [CrossRef]

43. Crampin, S. Calculable fluid-rock interactions. J. Geol. Soc. 1999, 156, 501-514. [CrossRef]

44. Soleimani, M. Naturally fractured hydrocarbon reservoir simulation by elastic fracture modeling. Pet. Sci. 2017, 14, $286-301$. [CrossRef]

45. Chen, C.-C.; Chen, C.-S.; Shieh, C.-F. Crustal Electrical Conductors, Crustal Fluids and 1999 Chi-Chi, Taiwan, Earthquake. Terr. Atmos. Ocean. Sci. 2002, 13, 367. [CrossRef]

46. Johnson, K.M.; Hsu, Y.-J.; Segall, P.; Yu, S.-B. Fault geometry and slip distribution of the 1999 Chi-Chi, Taiwan Earthquake imaged from inversion of GPS data. Geophys. Res. Lett. 2001, 28, 2285-2288. [CrossRef]

47. Yu, S.-B.; Kuo, L.-C.; Hsu, Y.-J.; Su, H.-H.; Liu, C.-C.; Hou, C.-S.; Lee, J.-F.; Lai, T.-C.; Liu, C.-C.; Liu, C.-L. Preseismic Deformation and Coseismic Displacements Associated with the 1999 Chi-Chi, Taiwan, Earthquake. Bull. Seism. Soc. Am. 2004, 91, 995-1012. [CrossRef]

48. Wu, W.-N.; Hsu, S.-K.; Lo, C.-L.; Chen, H.-W.; Ma, K.-F. Plate convergence at the westernmost Philippine Sea Plate. Tectonophysics 2009, 466, 162-169. [CrossRef]

49. Wang, Y.-J.; Ma, K.-F. Investigation of the Temporal Change in Attenuation Within the Ruptured Fault Zone of the 1999 Mw7.3 Chi-Chi, Taiwan Earthquake. Pure Appl. Geophys. 2014, 172, 1291-1304. [CrossRef]

50. Tatham, R.H.; McCormack, M.D. Multicomponent Seismology in Petroleum Exploration; Society of Exploration Geophysicists: Tulsa, OK, USA, 1991.

51. Thurber, C.; Roecker, S.; Ellsworth, W.; Chen, Y.; Lutter, W.; Sessions, R. Two-dimensional seismic image of the San Andreas Fault in the Northern Gabilan Range, central California: Evidence for fluids in the fault zone. Geophys. Res. Lett. 1997, 24, 1591-1594. [CrossRef] 